Article

\title{
Effect of Micronutrient and Probiotic Fortified Yogurt on Immune-Function of Anti-Retroviral Therapy Naive HIV Patients
}

Ruben Hummelen ${ }^{1,2, \dagger, *}$, Jaimie Hemsworth ${ }^{2,3, \dagger,+, *}$, John Changalucha ${ }^{4}$, Nicodemus L. Butamanya ${ }^{5}$, Sharareh Hekmat ${ }^{2,3}$, J. Dik F. Habbema ${ }^{1}$ and Gregor Reid ${ }^{2,6}$

1 Department of Public Health, Erasmus MC University Medical Center Rotterdam P.O. Box 2040, 3000 CA Rotterdam, The Netherlands; E-Mail: j.d.f.habbema@erasmusmc.nl

2 Canadian Research \& Development Centre for Probiotics, Lawson Health Research Institute, 268 Grosvenor Street, N6A 4V2, London, Ontario, Canada; E-Mails: hekmat@uwo.ca (S.H.); gregor@uwo.ca (G.R.)

3 Division of Food and Nutritional Sciences at Brescia University College, The University of Western Ontario, N6G 1H2, 1285 Western Road, London, Ontario, Canada

4 National Institute for Medical Research, Mwanza Research Centre, P.O. Box 1462, Mwanza, Tanzania; E-Mail: jchangalucha@yahoo.com

5 Sekou-Toure Regional Hospital, P.O. Box 132, Mwanza, Tanzania; E-Mail: nicobutamanya@yahoo.com

6 Departments of Microbiology, Immunology and Surgery, The University of Western Ontario, N6A 5C1, London, Ontario, Canada

$\dagger$ These authors contributed equally to this work.

* Current address: London School of Hygiene \& Tropical Medicine, University of London, WC1E 7HU, London, UK

* Authors to whom correspondence should be addressed; E-Mails: rubenhummelen@gmail.com (R.H.); jaimie.hemsworth@1shtm.ac.uk(J.H.); Tel.: +31-614432336; Fax: +1-519-646-6031.

Received: 18 August 2011; in revised form: 23 September 2011 / Accepted: 12 October 2011 / Published: 21 October 2011

Abstract: Background: Micronutrient supplementation has been shown to reduce the progression of HIV but does not have an effect on the intestinal barrier or the intestinal microbiota of HIV patients. Studies have suggested that probiotics could potentially 
complement micronutrients in preserving the immune-function of HIV patients. Objective: Assess the impact of micronutrient supplemented probiotic yogurt on the immune function of HIV patients. Design: We performed a randomized, double blind, controlled trial with CD4 count as primary outcome among HIV patients naïve to anti-retroviral treatment. Secondary outcomes included hematological parameters, incidence of diarrhea and clinical symptoms. A total of $112 \mathrm{HIV}$ patients were randomized to receive a micronutrient fortified yogurt with $(n=55)$ or without additional probiotic Lactobacillus rhamnosus GR-1 ( $n=57)$ for four weeks. Results: An average decline in CD4 count of -70 cells $/ \mu \mathrm{L}$ (95\% CI: -154 to -15 ) was observed in the micronutrient, probiotic group versus a decrease of -63 cells $/ \mu \mathrm{L}(95 \% \mathrm{CI}:-157$ to -30$)$ in the micronutrient control group $(p=0.9)$. Additional probiotic supplementation was well tolerated and not associated with adverse events. No difference between groups was detected in incidence of diarrhea or clinical symptoms. An improvement of hemoglobin levels was observed for all subjects, based upon a mean difference from baseline of $1.4 \mathrm{~g} / \mathrm{L}(\mathrm{SD}=6)(p=0.02)$. Conclusion: The addition of probiotics to a micronutrient fortified yogurt was well tolerated by HIV patients but was not associated with a further increase in CD4 count after one month.

Keywords: micronutrients; probiotics; HIV; Lactobacillus; immune system

\section{Introduction}

Poor nutritional status among people living with HIV is a common problem [1] and has been associated with enhanced HIV progression in numerous observational studies [2,3]. Impaired immune function of people living with HIV is further compounded by a deleterious impact of the virus on the gut-associated mucosal immune system [4,5], which presumably results in translocation of microbial products from the intestinal tract [6,7], an aberrant intestinal microbiota [8,9], and an increased incidence of intestinal infections [10]. Microbial translocation as a result of impaired gut barrier function, in combination with low micronutrient levels, may further enhance the progression of HIV $[6,11,12]$.

Supplementation of micronutrients, most notably B-complex, vitamin $\mathrm{C}$ and $\mathrm{E}$, can reduce the progression and mortality of HIV [13-17], but does not impact intestinal barrier impairment [18]. Supplementation of vitamin A as single supplement does not appear to reduce the progression of HIV or mortality related to the disease in adults $[15,19]$.

Probiotics, defined as "live microorganisms which, when administered in adequate amounts, confer a health benefit on the host" [20], have been used with some success to preserve the immune-function of people living with HIV in the following studies. A small randomized controlled trial (RCT) was performed in Brazil among 77 children infected with HIV. Half of the children received a supplement with probiotic strain Bifidobacterium bifidum and Streptococcus thermophilus for two months. After the two month period, CD4 counts among the treatment group increased 118 cells $/ \mu \mathrm{L}$ versus a decrease of 42 cells $/ \mu \mathrm{L}$ among the placebo group $(p=0.05)$ [21]. Another small pilot RCT in Nigeria discovered a small, but statistically significant effect, of four weeks of Lactobacillus rhamonus GR-1 and Lactobacillus reuteri RC-14 supplementation on the CD4 count of $24 \mathrm{HIV}$ infected women. The 
treatment group showed an increase in $\mathrm{CD} 4$ of 6.7 cells $/ \mu \mathrm{L}$ compared to a decrease of 2.2 cells $/ \mu \mathrm{L}$ in the control group $(p=0.05)$ [22]. Lastly, an observational study in Tanzania found that yogurt supplemented with Lactobacillus rhamnosus GR-1 increased the CD4 count with 0.28 cells/ $\mu \mathrm{L} /$ day ( $p=0.003$ ) among HIV infected men and women in Tanzania [23]. The mechanisms are believed to involve enhancing the gut barrier function [24,25], alleviating systemic inflammation [26,27], or reducing the duration of gastro-intestinal infections [28] (reviewed in [29]).

Despite massive efforts, only one out of three people in need of anti-retroviral treatment (ART) currently have access to the treatment [30]. The application of a food-based intervention, targeting both micronutrient deficiencies and an impaired gut-associated mucosal immune system, could provide an optimal adjunctive intervention to potentially delay the progression of HIV. Since 2005, a small community kitchen in Tanzania has produced yogurt supplemented with probiotics using Lactobacillus rhamnosus GR-1 [31]. We initiated a randomized, double-blind, placebo controlled study to assess whether the addition of probiotic L. rhamnosus GR-1 to a micronutrient fortified yogurt could positively impact the immune function of HIV patients. We selected L. rhamnosus GR-1 for its potential to reduce the translocation of Salmonella typhimurium from the gut to distant organs, as assessed in a mouse model [32], reduce systemic inflammation in a population with inflammatory bowel disease [33], and to increase the CD4 count in an HIV infected population [23].

\section{Experimental Section}

\subsection{Study Design}

The primary outcome was the mean change of CD4 count from baseline to 4 weeks follow-up. Secondary outcomes included hematology indicators (creatinine, albumin, alanine transaminase (ALT), and full blood count), incidence of diarrheal episodes, symptoms, physical energy and their ability to perform activities of daily living. Inclusion criteria were; confirmed HIV infection, naïve to ART and not eligible for ART initiation (i.e., CD4 count $\geq 200$ with WHO stage I or II infection or CD4 count $\geq 350$ and CDC stage III infection [34]), ability to attend the clinic every other day, $\geq 18$ years of age, not pregnant or lactating, and with no known lactose intolerance or milk allergy. We calculated a sample size of 49 per treatment arm to detect a within person difference of 15 cells/ $\mu \mathrm{L}$ in CD 4 count between the groups with a power of $90 \%$. The calculation assumed an attrition rate of $25 \%$ and a standard deviation of 20 cells $/ \mu \mathrm{L}$ within-person change in CD4 count. The Medical Research Coordinating Committee of the National Institute for Medical Research, Tanzania, approved the study design and protocol. Participants were informed of the purpose of the trial and gave their signed or thumb printed informed consent before participation. All study procedures were in concordance with the declaration of Helsinki of 1975, as revised in 2008.

\subsection{Study Subjects and Data Collection}

Recruitment took place at Shaloom health centre and at Sekou-Toure Regional Hospital, Mwanza, Tanzania from June to July 2008. Randomization and follow-up were conducted at Sekou-Toure regional hospital and extended until August 2008. During the baseline visit, a physical examination was performed by a physician, blood was taken to perform biochemical and hematological measurements 
and a structured interview was performed on demographics, medical history, and physical energy levels. The participants recorded the occurrence of diarrheal episodes using a diary, which was collected at each visit. Diarrhea was defined as three or more loose or watery stools in a 24-h period [35].

Participants were randomized to receive a yogurt that was fortified solely with micronutrients (control group) or was fortified with both micronutrients and L. rhamnosus GR-1 (probiotic group) for 4 weeks. Both yogurts were indistinguishable in taste or appearance. Subjects were consecutively assigned to one of the two treatment codes according to a computer generated schedule in blocks of 10 . The batches of yogurt were coded by a researcher not involved with data collection to ensure that neither the researchers nor the subjects were aware of their treatment assignments. Participants were asked to return to the clinic every other day to receive a two-day supply of yogurt of which one portion was consumed in the clinic to ensure at least 50\% adherence. Subjects returned after 4 weeks for the follow-up visit and were encouraged throughout the duration of the study to report any adverse events or changes in their condition. The procedures of the baseline visit were repeated exactly at the follow-up visit, with additional questions on adverse events. Participants who did not arrive at their follow-up visit were contacted by phone.

\subsection{Intervention}

The nutrient premix blend was provided by Fortitech Strategic Nutrition (Schenectady, New York, NY, USA), for which the concentrations of nutrients per portion of yogurt (125 mL) are summarized in Table 1. We based the formulation on that described by Kaiser et al. [17], but reduced the concentrations of the micronutrients to acceptable physiological levels that were also compatible with inclusion into yogurt. Preparation of the probiotic stock culture took place at National Institute for Medical Research (NIMR), Mwanza, and the organism was added to yogurt produced by a trained group of local women. The viability and abundance of the probiotic strain in the yogurt was assured for every batch using procedures previously described [36]. Overall, a mean $1.23 \times 10^{9}$ colony forming units/mL of L. rhamnosus GR-1 was found in the probiotic yogurt resulting in an intended dose of $15.38 \times 10^{10}$ colony forming units/day.

\subsection{Laboratory Measurements}

The laboratory measurements were performed at the NIMR, according to good laboratory practices. At baseline and at 4 weeks the CD4 count was measured using the Partec FACS (Partec GmbH, Münster, Germany), hematological parameters were measured using the Beckman Coulter AcT5 Diff Al (Beckman Coulter, Brea, CA, USA) and biochemistry parameters using the Synchron CX ${ }^{\circledR} 4$ PRO (Beckman Coulter, Brea, CA, USA).

\subsection{Analyses}

All analyses were performed on an intent-to-treat basis. The plan of data analysis was clearly established and stated in the study protocol before start of the study. Normally-distributed continuous (CD4 count, hematology parameters) data were compared using within-subject differences from baseline to follow-up, and tested using an unpaired students $t$-test. To assess the effect of the CD4 
count, HIV symptoms, BMI and anemia at baseline on the treatment response, a linear regression model was fitted. Categorical data (baseline characteristics) were compared using a $\chi^{2}$ test. All tests were performed two-sided at the $\alpha=0.05$ level with no adjustments made for multiple comparisons. Compliance with the study treatment was calculated as the number of days the participant consumed the yogurt divided by the total number of days the yogurt should have been consumed. Data was stored in an Access database and analyzed using SPSS 15.0 software.

Table 1. Probiotic and micronutrient content of the yogurts.

\begin{tabular}{lc}
\hline Ingredient & Amount/125 g \\
\hline Lactobacillus rhamnosus GR-1 * & $10^{9} \mathrm{CFU} / \mathrm{mL}$ \\
Vitamin A (as Beta carotene and Palmitate) & $1500 \mathrm{IU}$ \\
Vitamin E (as acetate) & $5.7 \mathrm{IU}$ \\
Niacinamide & $3.8 \mathrm{mg}$ \\
Vitamin B1 (thiamin) & $0.3 \mathrm{mg}$ \\
Vitamin B12 (cyanocobalamin) & $0.6 \mu \mathrm{g}$ \\
Vitamin B6 (pyroxine) & $0.3 \mathrm{mg}$ \\
Vitamin C (ascorbic acid) & $21 \mathrm{mg}$ \\
Iron (as ferric pyrophosphate) & $3.3 \mathrm{mg}$ \\
Selenium (sodium selenite) & $13.8 \mu \mathrm{g}$ \\
Zinc (zinc sulphate) & $2.4 \mathrm{mg}$ \\
DHA (omega-3 from fish oil) & $13 \mathrm{mg}$ \\
EPA (omega-3 from fish oil) & $19 \mathrm{mg}$ \\
\hline
\end{tabular}

$\mathrm{CFU}=$ Colony forming units; * Only in probiotic-supplemented yogurt.

\section{Results}

\subsection{Baseline Characteristics}

A total of 148 patients were screened for participation and 112 patients were enrolled. After randomization one participant in the control group was diagnosed with Kaposi's sarcoma and excluded from analyses according to exclusion criteria, as this indicated that a WHO stage IV had been present at baseline. Of 55 participants in the probiotic group, 52 completed follow-up versus all 56 participants in the control group ( $p=0.1$ ) (Figure 1). At baseline, 21 out of $53(40 \%)$ in the probiotic group had HIV-related symptoms upon physical examination (oral thrush, oral ulcers or maculo-papular rash), compared to 12 out of $55(21 \%)$ in the control group $(p=0.03)$. There was no difference in the median time living with HIV between the probiotic group (791 days, range 57-3511) and the placebo group (584 days, range 31-3458) (Wilcoxon rank test, $p=0.2$ ). Other baseline characteristics were comparable between the groups (Table 2). Overall, 92 out of 109 (84\%) participants had low serum albumin $(\leq 36 \mathrm{~g} / \mathrm{L})$ and 43 out of 97 tested $(44 \%)$ had anemia at baseline (hemoglobin $\leq 110 \mathrm{~g} / \mathrm{L}$ ) (Table 3). Compliance was excellent, among the probiotic group the product was consumed at a mean 98\% (95\% CI: 97-100) of days required compared to 96\% (95\% CI: 93-100) among the control group $(p=0.2)$. 
Figure 1. Trial profile.

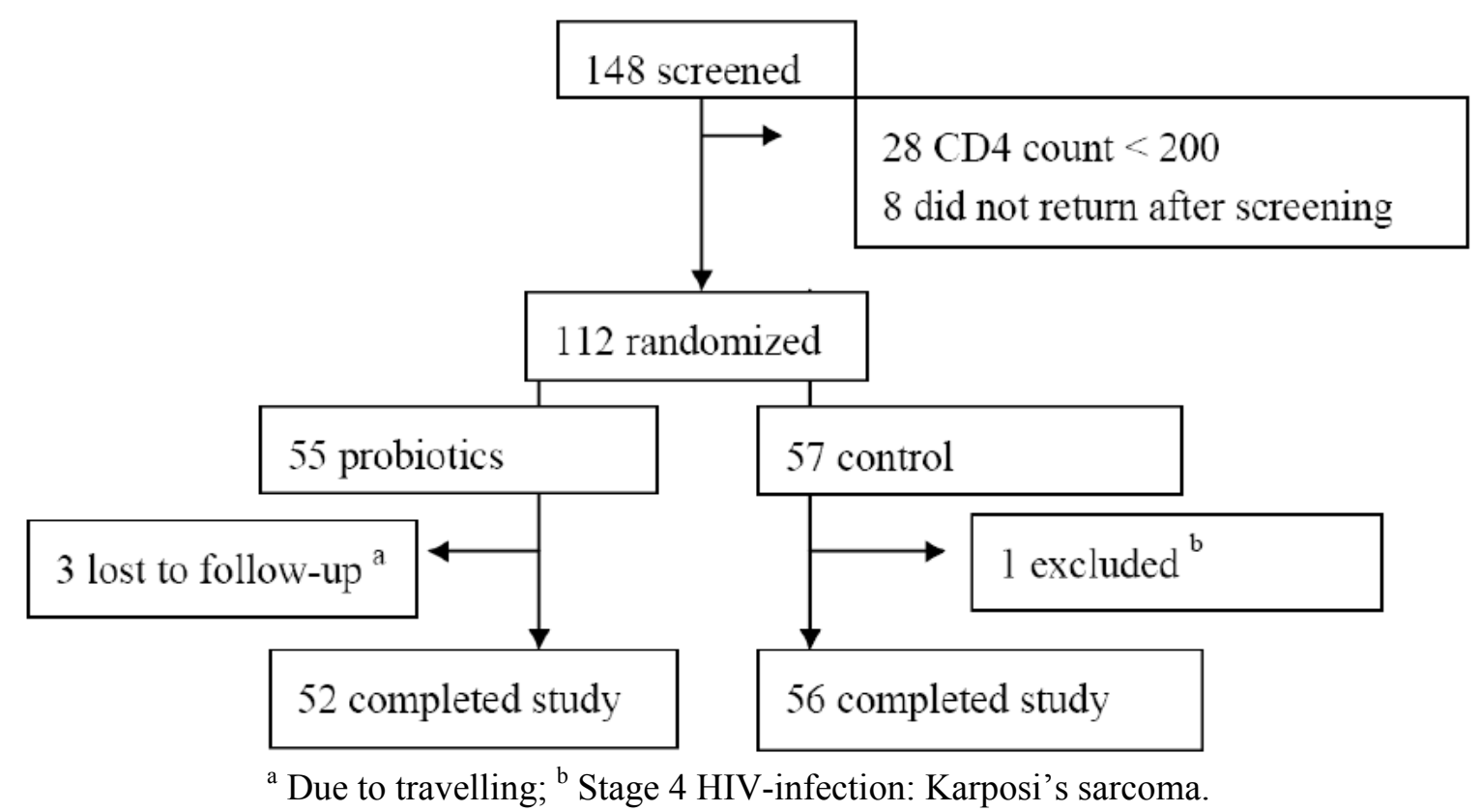

Table 2. Baseline characteristics of the treatment groups. In a few cases, data were not obtained.

\begin{tabular}{|c|c|c|c|c|}
\hline Characteristic $^{\text {a }}$ & Reference & $\begin{array}{c}\text { Probiotics } \\
n=55\end{array}$ & $\begin{array}{c}\text { Control } \\
n=56 \\
\end{array}$ & $P$ \\
\hline Gender female & & $47(86 \%)$ & $48(86 \%)$ & 1.0 \\
\hline \multirow[t]{2}{*}{ Age (years) } & $<30$ & $10(19 \%)$ & $8(15 \%)$ & 0.6 \\
\hline & $\geq 30$ & $44(81 \%)$ & $46(85 \%)$ & \\
\hline \multirow[t]{2}{*}{ Water source } & Pipe & $45(83 \%)$ & $41(73 \%)$ & 0.2 \\
\hline & Well & $9(17 \%)$ & $15(27 \%)$ & \\
\hline \multirow{2}{*}{ Working ability } & Unable & $5(10 \%)$ & $5(9 \%)$ & 1.0 \\
\hline & Able & $47(90 \%)$ & $51(91 \%)$ & \\
\hline \multirow[t]{4}{*}{ Marital status ${ }^{b}$} & Widow & $18(33 \%)$ & $24(43 \%)$ & 0.8 \\
\hline & Divorced & $12(22 \%)$ & $16(28 \%)$ & \\
\hline & Married & $19(34 \%)$ & $15(27 \%)$ & \\
\hline & Single & $6(11 \%)$ & $1(2 \%)$ & \\
\hline \multirow[t]{2}{*}{$\begin{array}{c}\text { Diagnosed with HIV } \\
\text { (years) }\end{array}$} & $<1$ & $18(33 \%)$ & $22(39 \%)$ & 0.5 \\
\hline & $\geq 1$ & $37(67 \%)$ & $34(61 \%)$ & \\
\hline \multirow[t]{3}{*}{ CD4 Count (cells $/ \mathrm{mm}^{3}$ ) } & $<350$ & $26(47 \%)$ & $30(54 \%)$ & 0.5 \\
\hline & $351-500$ & $12(22 \%)$ & $14(25 \%)$ & \\
\hline & $\geq 501$ & $17(31 \%)$ & $12(21 \%)$ & \\
\hline \multirow[t]{3}{*}{ WHO disease stage $^{b}$} & 1 & $39(75 \%)$ & $45(80 \%)$ & 0.5 \\
\hline & 2 & $5(10 \%)$ & $4(7 \%)$ & \\
\hline & 3 & $8(15 \%)$ & $7(13 \%)$ & \\
\hline Any HIV related symptom ${ }^{\mathrm{c}}$ & & $21(38 \%)$ & $12(21 \%)$ & 0.03 \\
\hline
\end{tabular}


Table 2. Cont.

\begin{tabular}{ccccc}
\hline BMI & $<18.5 \mathrm{~kg} / \mathrm{m}^{2}$ & $1(2 \%)$ & $6(11 \%)$ & 0.1 \\
\hline Anemia (Hemoglobin) & $<110 \mathrm{~g} / \mathrm{L}$ & $22(40 \%)^{\mathrm{d}}$ & $21(38 \%)$ & 0.6 \\
\hline Hypoalbuminemia (Albumin) & $<36 \mathrm{~g} / \mathrm{L}$ & $43(78 \%)^{\mathrm{e}}$ & $49(88 \%)$ & 0.4 \\
\hline Clotrimoxazole use & & $16(29 \%)$ & $12(21 \%)$ & 0.4 \\
\hline Vitamin B complex use & & $6(11 \%)$ & $4(7 \%)$ & 0.5 \\
\hline
\end{tabular}

BMI = Body Mass Index. ${ }^{a}$ The following categories have missing values: Age (3), water source (1), Functional Status (3), BMI (4), WHO disease stage (3), Any HIV related symptom (3). ${ }^{\mathrm{b}}$ The following subgroups were combined for valid testing: Marital status: "Widow" with "divorced" with "single"; WHO disease stage: stage " 2 " with "3"; " Any HIV related symptom = oral thrush, oral ulcers or maculo-papular rash on physical examination. As not all data could be obtained, some of the calculations in the table are not for the full 55 or 56 participatants; ${ }^{\mathrm{d}}$ there were missing biological samples for 8 of the participants at baseline in the probiotic group, i.e., 22 of 47 showed low hemoglobin levels in the probiotic group; ${ }^{\mathrm{e}}$ there were two missing samples for albumin in the probiotic group.

Table 3. Changes in hematology and biochemistry parameters from baseline to follow-up.

\begin{tabular}{ccccccccc}
\hline & & \multicolumn{4}{c}{ Probiotics } & \multicolumn{3}{c}{ Control } \\
\hline Parameter & Reference & Base $^{\mathbf{a}}$ & FU & \% Change & Base & FU & \% Change & $\boldsymbol{p}^{\mathbf{c}}$ \\
& Value/unit & n/total & n/total & mean $\pm \mathrm{SD}$ & n/total & n/total & mean $\pm \mathrm{SD}$ & \\
\hline Creatinine & $\geq 139 \mu \mathrm{mol} / \mathrm{L}$ & $1 / 52$ & $0 / 50$ & $-1 \pm 17$ & $0 / 56$ & $1 / 56$ & $1 \pm 29$ & 0.6 \\
Albumin & $<36 \mathrm{~g} / \mathrm{L}$ & $43 / 53$ & $46 / 50$ & $0 \pm 20$ & $49 / 56$ & $51 / 56$ & $-1 \pm 24$ & 0.9 \\
ALT & $\geq 50 \mathrm{IU} / \mathrm{L}$ & $2 / 53$ & $2 / 50$ & $-3 \pm 9$ & $2 / 56$ & $1 / 56$ & $1 \pm 10$ & 0.1 \\
Hemoglobin & $<110 \mathrm{~g} / \mathrm{L}$ & $22 / 47$ & $19 / 43$ & $-9 \pm 53$ & $21 / 50$ & $17 / 47$ & $4 \pm 53$ & 0.3 \\
Platelets & $<150 \times 10^{9} / \mathrm{L}$ & $3 / 47$ & $3 / 43$ & $-13 \pm 47$ & $4 / 50$ & $4 / 47$ & $-5 \pm 23$ & 0.3 \\
RBC & $<4 \times 10^{12} / \mathrm{L}$ & $29 / 47$ & $17 / 43$ & $-10 \pm 53$ & $33 / 50$ & $14 / 47$ & $-6 \pm 66$ & 0.7 \\
WBC & $\geq 11 \times 10^{9} / \mathrm{L}$ & $0 / 48$ & $0 / 43$ & $-1 \pm 18$ & $1 / 50$ & $0 / 47$ & $-7 \pm 21$ & 0.2 \\
Neutrophils & $\geq 80 \%$ & $0 / 44$ & $0 / 37$ & $-6 \pm 38$ & $0 / 46$ & $0 / 45$ & $-12 \pm 72$ & 0.6 \\
Lymphocytes & $\geq 50 \%$ & $13 / 47$ & $13 / 43$ & $-6 \pm 36$ & $11 / 50$ & $14 / 47$ & $10 \pm 72$ & 0.2 \\
Monocytes & $\geq 10 \%$ & $0 / 47$ & $0 / 43$ & $1 \pm 12$ & $0 / 50$ & $0 / 47$ & $-1 \pm 15$ & 0.6 \\
Eosinophils & $\geq 5 \%$ & $23 / 44$ & $19 / 37$ & $-7 \pm 16$ & $26 / 46$ & $28 / 45$ & $-1 \pm 12$ & 0.1 \\
Basophils & $\geq 2 \%$ & $0 / 47$ & $0 / 43$ & $-2 \pm 4$ & $0 / 50$ & $0 / 47$ & $-1 \pm 4$ & 0.1 \\
\hline
\end{tabular}

Base $=$ Baseline $; \mathrm{FU}=$ Follow-up; $\mathrm{SD}=$ Standard Deviation; ALT $=$ Alanine transaminase; $\mathrm{RBC}=$ Red blood cells; $\mathrm{WBC}=$ White blood cells; ${ }^{\mathrm{a}}$ Number of participants above or below reference value; ${ }^{\mathrm{b}}$ Mean within-subject change from baseline to follow-up; ${ }^{\mathrm{c}}$ Tested using within-subject change from baseline to follow-up.

\subsection{Primary Outcome}

The probiotic group experienced an average decline of -70 cells $/ \mu \mathrm{L}(95 \% \mathrm{CI}:-154$ to -15 cells $/ \mu \mathrm{L})$ CD4 cells from baseline versus a decline of -63 cells $/ \mu \mathrm{L}(95 \% \mathrm{CI}:-157$ to -30$)$ in the control group $(p=0.9)$. Adjusting for baseline CD4 count, HIV symptoms, BMI or anemia yielded similar results and did not change this finding. The baseline CD4 count was highly predictive of the development of the CD4 count during follow-up. Overall, those with a CD4 count of 200-350 experienced an increase in CD4 count of 67 cells $/ \mu \mathrm{L}$ (95\% CI: -19 to 152 ) during follow-up. This in 
contrast to those with a CD4 count of $\geq 350$ cells $/ \mu \mathrm{L}$ at baseline who experience an average decline of 187 cells $/ \mu \mathrm{L}$ (95\% CI: -372 to -136$)$ during follow-up. Among those with a CD4 count of 200-350 cells/ $\mu \mathrm{L}$, HIV related symptoms were more common (21/53) than those with a CD4 count of $\geq 350$ cells $/ \mu \mathrm{L}(12 / 55)(p=0.05)$. No differences were detected in the number of days living with HIV between those with a CD4 count of $200-350$ or $\geq 350$ cells $/ \mu \mathrm{L}$ at baseline.

\subsection{Secondary Outcomes}

No differences were found in self-reported symptoms (mouth ulcers, coughing, fever, nausea, and stomach pain), self-reported physical energy level or ability to perform daily activities following the one month treatment. Among the probiotic group, 13 out of $51(26 \%)$ participants experienced diarrhea for at least one day during the intervention, which was not different from the control group, where 16 out of $54(30 \%)$ experienced diarrhea $(p=0.6)$. Overall, an improvement of hemoglobin levels was observed with a mean difference from baseline of $1.4 \mathrm{~g} / \mathrm{L}(\mathrm{SD}=6)(p=0.02)$.

\subsection{Adverse Events}

In the probiotic group, four participants reported an adverse event including one with stomach pain, two with nausea and one with diarrhea as the main adverse event. In the control group, six participants reported an adverse event, among which one subject reported numbness in hands and feet, one stomach pain and three reported having diarrhea. Only the numbness of hands and feet symptoms were scored severe by a physician but this was unlikely to be related to the study intervention. The other adverse events were rated mild or moderately. No differences were detected in biochemical or hematological parameters between the probiotic and control group (Table 3).

\section{Discussion}

In this randomized, controlled study, the addition of a probiotic Lactobacillus to a micronutrient fortified yogurt did not further substantiate the effect on the CD4 count or clinical symptoms of HIV-infected adults with a starting CD4 count of $\geq 200$ cells $/ \mu \mathrm{L}$. The micronutrient fortified probiotic yogurt was well tolerated among the participants and was not associated with adverse events. This result somewhat contrasts previous studies showing a positive effect of probiotic supplementation on CD4 counts [21-23], but these were not performed with micronutrient supplementation which herein and elsewhere [17] independently can affect on CD4 count. One small RCT in Nigeria had used L. reuteri RC-14 in combination with the strain studied here (L. rhamnosus GR-1) [22], while the observational study had used L. rhamnosus GR-1 alone [23]. The RCT in Brazil had used a combination of different strains for children treated with ART (Bifidobacterium bifidum and Streptococcus thermophilus) [21]. The apparent contradiction could have two explanations. Firstly, the study in Nigeria [22] had found a standard deviation of the change in CD4 count of approximately 10 cells $/ \mu \mathrm{L}$ during a 4 week follow-up while in our population we found a standard 330 cells $/ \mu \mathrm{L}$ during the same follow-up period. Because we used the previously reported standard deviation for sample size calculations, our study had reduced power to show an effect. The Nigerian study had recruited a homogenous group of women having moderate diarrhea symptoms, which could explain the 
difference in variability in CD4 counts. Secondly, our treatment period could have been too short to show an effect on CD4 count. Upon reflection, the use of measurements of the intestinal barrier function (e.g., lipo-polysaccharide or lactoferrin: mannitol ratio [6,7]), or immune activation and regulation (e.g., CD4+/CD25+ and FoxP3 lymphocytes [30,37]) could have served as a screening tool to assess potential benefits of probiotics within an HIV infected population. Therefore, we suggest these markers to be used in future studies to screen or assess the potential effect of specific probiotic strains.

The overall change in CD4 count of a mean -70 cells/ $\mu \mathrm{L}$ (CI 95\%; -157 to -30 ) was lower than normally observed among HIV patients $[38,39]$. The decrease among both groups was not expected as the micronutrient formula tested by Kaiser et al. [17], on which our micronutrient formula was based, had shown an increase in CD4 count. The nutrient formula used in this study was not intended to provide a high dose of micronutrients at multiple times of the Dietary Reference Intake (DRI) [15,17], but rather an excellent dietary source at $25 \%$ of the DRI [40] to an already nutritious food (yogurt). The decrease in CD4 count may be explained by a tendency of parameters to decline when selected above a specific value (i.e., regression to the mean). Since HIV patients were included only with a CD4 count $\geq 200$ cells $/ \mu \mathrm{L}$, a greater decline in CD4 count could have been observed than within an unselected population. This explanation is supported by the finding that participants with a CD4 count $\geq 350$ cells $/ \mu \mathrm{L}$ at baseline experienced decrease $(-187$ cells $/ \mu \mathrm{L})$ while those with a CD4 count of $<350$ cells $/ \mu \mathrm{L}$ experience an increase in CD4 count $(67$ cells $/ \mu \mathrm{L})$. The impact of this mechanism on the results was assessed by adjusting for baseline CD4 count levels; this adjustment did not significantly change the inferences of the study, and is therefore likely to be modest. The decrease might further be explained in part by the fact that almost half of the participants had anemia, which has been observed to be factors for enhanced HIV progression [41]. Again, it is easy in hindsight to consider how better the study could have been set up, but clearly lessons have been learned that even with limited resources, attempts to identify potential responders to the treatment should be made [41]. In addition, future studies of longer duration should be performed to assess whether benefits take longer to accrue.

\section{Conclusions}

In conclusion, the addition of a probiotic strain to a yogurt already supplemented with micronutrients was well tolerated by people living with HIV with a CD4 count $\geq 200$ cells/ $\mu \mathrm{L}$, but was not associated with further preservation of the immune-function over a one month period. The fact that a yogurt could be made in a community kitchen that is acceptable in terms of taste and texture, and contains a complex mixture of nutritional supplements, offers some hope that grass root, nutrition-based approaches can potentially be found that contribute to the quality of life of people living with HIV.

\section{Acknowledgments}

We would like to sincerely thank our Tanzanian partners Judith Charles, Wilkister Karoko, Flora Masanja, Oswald Kaswamila, Julius Mngara, George Ogweno, Aura Andreassen, and Simon Buhalata for their expert assistance and hard work during the conduct of this study. We appreciate the dedication and excellent contribution of our Canadian team of Lesley Carmichael, Tara Koyama, Simon Lam, Kate Crowley and Wayne Miller and we acknowledge some financial support of 
AFMnet Canada towards the conduct of this study. Lastly, we wish to thank the staff and volunteers of the Western Heads East initiative of the University of Western Ontario for providing the inspiration and infrastructure which made this study possible.

\section{Conflict of Interest}

G.R. no longer owns patents of L. rhamnosus GR-1 which cover uro-genital applications, and neither he nor any of the other authors have any conflicts of interest.

\section{References}

1. Beach, R.; Mantero-Atienza, E.; Shor-Posner, G. Specific nutrient abnormalities in asymptomatic HIV-1 infection. AIDS 1992, 6, 701-708.

2. Tang, A.; Graham, N.; Saah, A. Effects of micronutrient intake on survival in human immunodeficiency virus type 1 infection. Am. J. Epidemiol. 1996, 143, 1244-1256.

3. Semba, R.D.; Graham, N.M.; Caiaffa, W.T.; Margolick, J.B.; Clement, L.; Vlahov, D. Increased mortality associated with vitamin A deficiency during human immunodeficiency virus type 1 infection. Arch. Intern. Med. 1993, 153, 2149-2154.

4. Mehandru, S.; Poles, M.A.; Tenner-Racz, K.; Horowitz, A.; Hurley, A.; Hogan, C.; Boden, D.; Racz, P.; Markowitz, M. Primary HIV-1 infection is associated with preferential depletion of CD4+ T lymphocytes from effector sites in the gastrointestinal tract. J. Exp. Med. 2004, 200, 761-770.

5. Lim, S.G.; Condez, A.; Lee, C.A.; Johnson, M.A.; Elia, C.; Poulter, L.W. Loss of mucosal CD4 lymphocytes is an early feature of HIV infection. Clin. Exp. Immunol. 1993, 92, 448-454.

6. Brenchley, J.M.; Price, D.A.; Schacker, T.W.; Asher, T.E.; Silvestri, G.; Rao, S.; Kazzaz, Z.; Bornstein, E.; Lambotte, O.; Altmann, D.; et al. Microbial translocation is a cause of systemic immune activation in chronic HIV infection. Nat. Med. 2006, 12, 1365-1371.

7. Wallet, M.A.; Rodriguez, C.A.; Yin, L.; Saporta, S.; Chinratanapisit, S.; Hou, W.; Sleasman, J.W.; Goodenow, M.M. Microbial translocation induces persistent macrophage activation unrelated to HIV-1 levels or T-cell activation following therapy. AIDS 2010, 24, 1281-1290.

8. Gori, A.; Tincati, C.; Rizzardini, G.; Torti, C.; Quirino, T.; Haarman, M.; Ben Amor, K.; van Schaik, J.; Vriesema, A.; Knol, J.; et al. Early impairment of gut function and gut flora supporting a role for alteration of gastrointestinal mucosa in human immunodeficiency virus pathogenesis. J. Clin. Microbiol. 2008, 46, 757-758.

9. Wolf, B.W.; Wheeler, K.B.; Ataya, D.G.; Garleb, K.A. Safety and tolerance of Lactobacillus reuteri supplementation to a population infected with the human immunodeficiency virus. Food Chem. Toxicol. 1998, 36, 1085-1094.

10. Kelly, P.; Todd, J.; Sianongo, S.; Mwansa, J.; Sinsungwe, H.; Katubulushi, M.; Farthing, M.J.; Feldman, R.A. Susceptibility to intestinal infection and diarrhoea in Zambian adults in relation to HIV status and CD4 count. BMC Gastroenterol. 2009, 9, 7.

11. Cassol, E.; Malfeld, S.; Mahasha, P.; van der Merwe, S.; Cassol, S.; Seebregts, C.; Alfano, M.; Poli, G.; Rossouw, T. Persistent microbial translocation and immune activation in HIV-1-infected South Africans receiving combination antiretroviral therapy. J. Infect. Dis. 2010, 202, 723-733. 
12. Hummelen, R.; Hemsworth, J.; Reid, G. Micronutrients, $N$-Acetyl cysteine, probiotics and prebiotics, a review of effectiveness in reducing HIV progression. Nutrients 2010, 2, 626-651.

13. Kanter, A.S.; Spencer, D.C.; Steinberg, M.H.; Soltysik, R.; Yarnold, P.R.; Graham, N.M. Supplemental vitamin B and progression to AIDS and death in black South African patients infected with HIV. J. Acquir. Immune Defic. Syndr. 1999, 21, 252-253.

14. Fawzi, W.W.; Msamanga, G.I.; Spiegelman, D.; Urassa, E.J.; McGrath, N.; Mwakagile, D.; Antelman, G.; Mbise, R.; Herrera, G.; Kapiga, S.; et al. Randomised trial of effects of vitamin supplements on pregnancy outcomes and $\mathrm{T}$ cell counts in HIV-1-infected women in Tanzania. Lancet 1998, 351, 1477-1482.

15. Fawzi, W.W.; Msamanga, G.I.; Spiegelman, D.; Wei, R.; Kapiga, S.; Villamor, E.; Mwakagile, D.; Mugusi, F.; Hertzmark, E.; Essex, M.; et al. A randomized trial of multivitamin supplements and HIV disease progression and mortality. N. Engl. J. Med. 2004, 351, 23-32.

16. Jiamton, S.; Pepin, J.; Suttent, R. A randomized trial of the impact of multiple micronutrient supplementation on mortality among HIV-infected individuals living in Bangkok. AIDS 2003, 17, 2461-2469.

17. Kaiser, J.D.; Adriana, M.C.; Ondercin, J.P.; Gifford, S.L.; Pless, R.F.; Baum, M.K. Micronutrient supplementation increases CD4 count in HIV-infected individuals on highly active antiretroviral therapy: A prospective, double-blinded, placebo-controlled trial. J. Acquir. Immune Defic. Syndr. 2006, 42, 523-528.

18. Kelly, P.; Shawa, T.; Mwanamakondo, S.; Soko, R.; Smith, G.; Barclay, G.R.; Sanderson, I.R. Gastric and intestinal barrier impairment in tropical enteropathy and HIV: limited impact of micronutrient supplementation during a randomised controlled trial. BMC Gastroenterol. 2010, $10,72$.

19. Fawzi, W.; Msamanga, G.; Spiegelman, D. Randomized trial of effects of vitamin supplements on pregnancy outcomes and T cell counts in HIV-1-infected women in Tanzania. Lancet 1998, 351, 1477-1482.

20. WHO/FAO. Evaluation of Health and Nutritional Properties of Powder Milk and Live Lactic Acid Bacteria; Food and Agriculture Organization of the United Nations and World Health Organization Expert Consultation Report: Cordoba, Argentina, 2001.

21. Trois, L.; Cardoso, E.M.; Miura, E. Use of probiotics in HIV-infected children: a randomized double-blind controlled study. J. Trop. Pediatr. 2008, 54, 19-24.

22. Anukam, K.C.; Osazuwa, E.O.; Osadolor, H.B.; Bruce, A.W.; Reid, G. Yogurt containing probiotic Lactobacillus rhamnosus GR-1 and L. reuteri $\mathrm{RC}-14$ helps resolve moderate diarrhea and increases CD4 count in HIV/AIDS patients. J. Clin. Gastroenterol. 2008, 42, 239-243.

23. Irvine, S.L.; Hummelen, R.; Hekmat, S.; Looman, C.W.; Habbema, J.D.; Reid, G. Probiotic yogurt consumption is associated with an increase of CD4 count among people living with HIV/AIDS. J. Clin. Gastroenterol. 2010, 44, 201-205.

24. Rosenfeldt, V.; Benfeldt, E.; Valerius, N.H.; Paerregaard, A.; Michaelsen, K.F. Effect of probiotics on gastrointestinal symptoms and small intestinal permeability in children with atopic dermatitis. J. Pediatr. 2004, 145, 612-616. 
25. Luyer, M.D.; Buurman, W.A.; Hadfoune, M.; Speelmans, G.; Knol, J.; Jacobs, J.A.; Dejong, C.H.; Vriesema, A.J.; Greve, J.W. Strain-specific effects of probiotics on gut barrier integrity following hemorrhagic shock. Infect. Immun. 2005, 73, 3686-3692.

26. Braat, H.; van den Brande, J.; van Tol, E.; Hommes, D.; Peppelenbosch, M.; van Deventer, S. Lactobacillus rhamnosus induces peripheral hyporesponsiveness in stimulated CD4+ T cells via modulation of dendritic cell function. Am. J. Clin. Nutr. 2004, 80, 1618-1625.

27. Giamarellos-Bourboulis, E.J.; Bengmark, S.; Kanellakopoulou, K.; Kotzampassi, K. Pro- and synbiotics to control inflammation and infection in patients with multiple injuries. J. Trauma 2009, 67, 815-821.

28. Allen, S.J.; Martinez, E.G.; Gregorio, G.V.; Dans, L.F. Probiotics for treating acute infectious diarrhoea. Cochrane Database Syst. Rev. 2010, CD003048; doi:10.1002/14651858.CD003048.pub3.

29. Hummelen, R.; Vos, A.P.; van't Land, B.; van Norren, K.; Reid, G. Altered host-microbe interaction in HIV: a target for intervention with pro- and prebiotics. Int. Rev. Immunol. 2010, 29, 485-513.

30. UNAIDS. MDG6: six things you need to know about the AIDS response today. Available online: http://data.unaids.org/pub/Report/2010/20100917_mdg6_report_en.pdf (accessed on 1 October 2010).

31. Wenner, M. A cultured response to HIV. Nat. Med. 2009, 15, 594-597.

32. Reid, G.; Charbonneau, D.; Gonzalez, S.; Gardiner, G.; Erb, J.; Bruce, A.W. Ability of Lactobacillus GR-1 and RC-14 to stimulate host defences and reduce gut translocation and infectivity of Salmonella typhimurium. Nutraceut Food 2002, 7, 168-173.

33. Baroja, M.L.; Kirjavainen, P.V.; Hekmat, S.; Reid, G. Anti-inflammatory effects of probiotic yogurt in inflammatory bowel disease patients. Clin. Exp. Immunol. 2007, 149, 470-479.

34. Ministry of Health, United Republic of Tanzania, National Guidelines for the Clinical Management of HIV/AIDS, 2005. Available online: http://www.collections.infocollections.org/ whocountry/en/d/Js6885e/15.3.1.html (accessed on 28 September 2010).

35. WHO. Diarrhoeal disease Factsheet No 330, August 2009. Available online: http://www.who.int/ mediacentre/factsheets/fs330/en/index.html (accessed on 1 October 2010).

36. Hekmat, S.; Soltani, H.; Reid, G. Growth and survival of Lactobacillus reuteri RC-14 and Lactobacillus rhamnosus GR-1 in yogurt for use as a functional food. Food Sci. Emerg. Technol. 2009, 10, 293-296.

37. van't Land, B.; Benlhassan-Chahour, K.; Rizzardini, G.; Vriesema, A.; Garssen, J.; Trabattoni, D.; Bray, D.; Gori, A.; Clerici, M. A specific mixture of prebiotic oligosaccharides reduces hyper-immune activation and improves NK cell cytolytic activity in HAART-naive HIV positive adults. In Proceedings of 15th Conference on Retroviruses and Opportunistic Infections (CROI), Boston, MA, USA, 3-6 February 2008.

38. Mermin, J.; Lule, J.; Ekwaru, J.P.; Malamba, S.; Downing, R.; Ransom, R.; Kaharuza, F.; Culver, D.; Kizito, F.; Bunnell, R.; et al. Effect of co-trimoxazole prophylaxis on morbidity, mortality, CD4-cell count, and viral load in HIV infection in rural Uganda. Lancet 2004, 364, $1428-1434$. 
39. Holmes, C.; Wood, R.; Badri, M.; Zilber, S.; Wang, B.; Maartens, G.; Zheng, H.; Lu, Z.; Freedberg, K.; Losina, E. CD4 Decline and incidence of opportunistic infections in Cape Town, South Africa: implications for prophylaxis and treatment. J. Acquir. Immune Defic. Syndr. 2006, 42, 464-469.

40. Dietary Reference Intakes: The Essential Guide to Nutrient Requirements; Otten, J.J., Hellwig, J.P., Meyers, L.D., Eds.; National Academy of Sciences: Washington, DC, USA, 2006.

41. O’Brien, M.E.; Kupka, R.; Msamanga, G.I.; Saathoff, E.; Hunter, D.J.; Fawzi, W.W. Anemia is an independent predictor of mortality and immunologic progression of disease among women with HIV in Tanzania. J. Acquir. Immune Defic. Syndr. 2005, 40, 219-225.

(C) 2011 by the authors, licensee MDPI, Basel, Switzerland. This article is an open access article distributed under the terms and conditions of the Creative Commons Attribution license (http,//creativecommons.org/licenses/by/3.0/). 